\title{
Development Research of a New Welding Manufacturing Quality Control and Management System (Case: China)
}

\author{
Xiaochen Yang, Paul Kah, Jukka Martikainen \\ Laboratory of Welding Technology, Lappeenranta University of Technology, Lappeenranta, Finland
}

Email address:

xiaochen.yang@lut.fi (Xiaochen Yang),paul.kah@lut.fi (P. Kah), jukka.martikainen@lut.fi (J. Martikainen)

To cite this article:

Xiaochen Yang, Paul Kah, Jukka Martikainen. Development Research of a New Welding Manufacturing Quality Control and Management System (Case: China). International Journal of Mechanical Engineering and Applications. Vol. 3, No. 6, 2015, pp. 120-126. doi: 10.11648/j.ijmea.20150306.14

\begin{abstract}
The Chinese welding industry is growing every year. Companies around the world are looking to use Chinese enterprises as their cooperation partners. However, the Chinese welding industry also has relatively low quality and weak management system. A modern, advanced welding management system appropriate for local socio-economic conditions is required to enable Chinese enterprises to enhance further their business development. This article designed and implemented a new welding quality management system in China. This new system is called 'welding production quality control management model system in China' (WQMC). Constructed on the basis of surveys and in-company interviews, the welding management system comprises the following different elements and perspectives: a 'Localized congenital existing problem resolution strategies ' (LCEPRS) database, a 'human factor designed training system' (HFDT) training strategy, the theory of modular design, ISO 3834 requirements, total welding management (TWM), and lean manufacturing (LEAN) theory. The paper also describes the design and implementation of a HFDT strategy in Chinese welding companies. Such training is an effective way to increase employees' awareness of quality and issues associated with quality assurance. The study identified widely existing problems in the Chinese welding industry and constructed a LCEPRS database that can be used to mitigate and avoid common problems. The work uses the theory of modular design, and TWM as tools for the implementation of the WQMC system. Analysis of the WQMC system effects indicates that its adoption has resulted in improved quality and reduced costs.
\end{abstract}

Keywords: Welding Quality Management, Training, WPS, ISO 3834, Total Welding Management

\section{Introduction}

The current situation in China as in many other developing and newly industrialized countries demands the development and implementation of a locally-appropriate, modern welding quality management and welding personnel training system that enables the attainment of an ideal balance of welding product quality, welding process costs and sustainable development. Such a training and management system will help staff to acquire appropriate and efficient working attitudes and procedures needed to increase production quality.

The aim of this paper is to construct a localized, sustainable, reliable and broadly applicable 'welding production quality control management system model for China' (WQMC) that can be used in small, medium, and large enterprises and is suitable for most industries in which welding is an inherent part. The system is based on the ISO
3834 standard and combines personnel training strategies, processes adaptations, and the implementation of existing problem-solving methods. The items listed below constitute the basic concepts and elements of the model, and each individual company can use the model to replace or enhance their daily work or management strategies:

- ISO 3834 and the documents with which it is necessary to conform to be able to claim conformity to the quality requirements. ISO 3834 forms the foundation of the model (WQMC) and defines its programmatic approach.

- A localized, human factor and psychology theory based welding personnel (welders, welding specialists, welding technicians, and welding engineers) training system for China. The training system is the origin of change and the guarantor of sustainable development of welding enterprises, factories and workshops.

- A long-term guidance and supervision system for welding processes. This system demands not only 
administrators but also staff to continue improving their tasks. Fast error correction guarantees the dynamism of enterprise development.

- A series of recommendations for improvements based on surveys, case studies, interviews and careful observation in over 30 Chinese welding factories or workshops. This series of recommendations are practical in nature and applicable also to welding enterprises in other developing and newly industrialized countries.[6, 7, 8, 9, 10, 11]

Together, the four items above constitute a comprehensive improvement model for welding enterprises in China and newly industrialized countries. This research is related to the research fields of welding technology, quality and knowledge management, psychology, and pedagogy and training.

Every enterprise requires its own management system to monitor internal affairs. An enterprise management system can be divided based on business functions into eleven parts: 1) plan management, 2) production management, 3) procurement management, 4) market management, 5) quality management, 6) logistic management, 7) financial management, 8) project management, 9) human resources management, 10) statistic management, and 11) information management [1]. Welding production enterprises often have the same above-mentioned eleven parts. Within any one enterprise, the listed management aspects are integrated into a whole management system in order to guarantee normal daily operations.

One management system for one company can include a number of different management sub systems. For example, a company may utilize the ISO 9001 quality management system, ISO 14001 environment management system, OHSAS 18001 occupational safety \& health management system, and ISO/IEC 27001 information security management system at the same time [2]. For a welding production or manufacturing company, the ISO 3834 welding quality management system should be integrated into the whole enterprise management system in order to ensure relatively high productivity, high quality, and low production costs. Within the context of this work, the theory of total welding management (TWM), the LEAN theory, the human factors designed training system, and the localization factors for China can be integrated into the management system in the same manner and thus the 'welding production quality control management system model for China (WQMC)' can be generated.

Fig. 1 illustrates the overall structure of the WQMC system, which comprises the following key elements:

- Normal enterprise management systems (NEMS): ISO 9001, ISO 14001, OHSAS 18001, ISO/IEC 27001 and other related management systems. The function of the NEMS is to provide the most basic foundation of the WQMC system;

- ISO 3834 welding quality management system;

- Human factor designed training system (HFDT);

- Total welding management (TWM) system, LEAN theory, and modular design model;

- Strategies for resolution of localized congenital existing problems (LCEPRS).

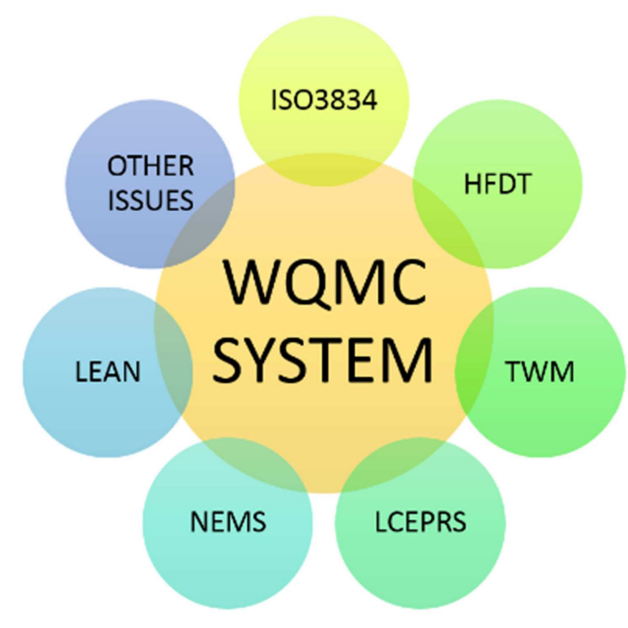

Fig. 1. Structure of WQMC and relationship to other management systems.

Before a company can implement the WQMC system, the NEMS should already be built inside company operations. While the nature of the NEMS and their implementation is clearly of importance, research of NEMS is beyond the scope of this study. Normally, if a manufacturing company is qualified by a system form NEMS, the 3rd party certification body must issue a certification document to the manufacturing company. However, ISO 3834 is of immediate relevance to the subject of this work and implementation steps for integration of ISO 3834 in the WQMC system are discussed in chapter 2 .

\section{Welding Quality System Implementation Based on the Tools Using in WQMC System}

The implementation steps of the ISO 3834 quality management system (the core of the WQMC system) are:

- Setting goals. The whole personnel participate in this process. During this period, the welding personnel must set out the difficulties and focus points for changes to the work processes;

- Placing the welding engineer or welding specialist in the right place in the personnel organization structure in order to give real power to the welding coordination teams to carry out necessary rectification work.

- Building an organizational structure between different departments inside the enterprise to ensure effective cooperation patterns and guarantee smooth communication channels.

- Communication of the goals. The whole personnel participates in a meeting to announce the goals of the activities in order to demonstrate the determination of the company;

- Setting of the quality policy. The quality policy should be set during the meeting, and the quality policy should be announced to customers;

- Documentation analysis and preparation. The welding coordination team do the documentation analysis work. 
This work involves checking which documents are missing and adding the necessary documents;

- Initiation of the inspection work. The welding coordination team, the welders and the inspection department launch the inspection work related to every aspect of welding quality. Surface treatment, welding consumable storage, the welding station, and maintenance work are the most crucial areas to check;

- Orientation of top management. The top managers have the responsibility to be familiar with and have knowledge of management strategies regarding the welding work. The confidence of the team is built by the top manager and passed on to all participants in the team;

- Continuous improvement process. A continuous improvement system is a requirement of the ISO 3834 standard. A PDCA cycle plan needs to be made and followed in order to ensure increasing productivity, increasing quality, and decreasing cost.

Welding factory in China which wants to implement the WQMC system needs to build the ISO 3834 welding quality management system as the core of WQMC. This is the first step to building the whole WQMC system. The LCEPRS strategies at the beginning steps of WQMC before ISO 3834 implementation and the HFDT strategy during the WQMC system building are useful tools to guarantee the effectiveness of the WQMC system implementation.

The modular design methodology is a useful tool in the WQMC system. In welding production processes, advanced methodology for design and manufacture is needed in order to increase quality and productivity, and decrease cost. The idea of modular design is to try to use similar design approaches or methods to meet different customer requirements for almost identical products. The products may have differences in dimensional aspects, but the main function should be the same. If modular design theory is used, a number of changes in the design and manufacture departments are usually required:

a) Revised design of jigs and fixtures for welding;

b) New arrangement of the layout of the welding workshop and its upstream and downstream processes;

c) Improved modular design awareness among designers;

d) Changes to the manufacturing habits of welders.

During the case project research, some commonly existing problems were found in the Chinese welding industry that clearly influenced quality, productivity and cost. These problems to some extent do not occur because of the welding industry itself but mainly because of the local Chinese culture, human factors and other related reasons. In the WQMC system, such problems are called 'localized congenital existing problems (LCEP)', and the solving method is called 'Localized congenital existing problem resolution strategies' (LCEPRS).

LCEP should be solved before the ISO 3834 implementation, or even before the NEMS implementation. On the other hand, some LCEPs may be recognized only during the implementation of ISO 3834 and later. In the
WQMC system, the identification and implementation of mitigation actions for LCEP, LCEPRS, will be largely complete after the survey and interview work, and before the implementation of ISO 3834.

More than 20 LCEPs were identified during the case project and on the basis of previous research. The LCEPs were noted through the use of surveys, interviews, discussions, observations, and the author's experiences. Some LCEPs will be similar to the problems discussed in previous chapters, but in the WQMC system, iterative improvement is a core concept. Knowledge of repeated problems will help enterprises prioritize areas requiring improvement.

The LCEPRS database is ready to update. Along with the development of the Chinese industry, and the deep research of this topic, more and new LCEPs is also can be found. The database will update according to the changing of the real situation. Fig. 2 illustrates the problem solving approach.

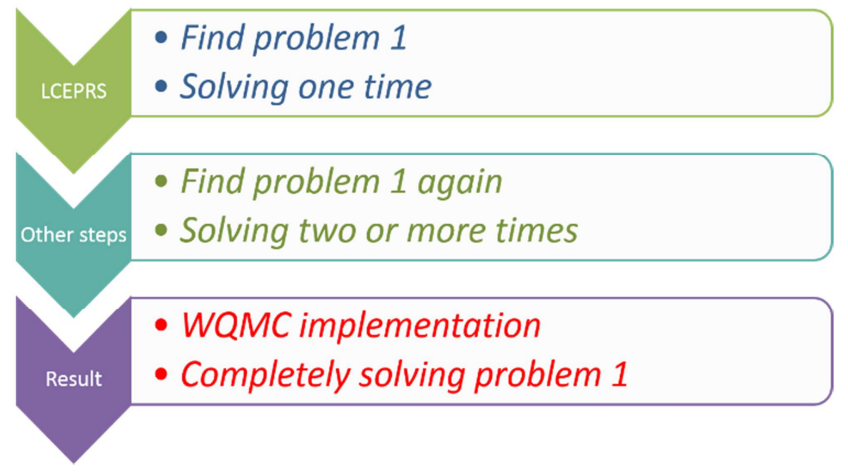

Fig. 2. Solving processes for repeated problems.

This process is also a concept from PDCA cycle. Problem 1 can be found in later steps, so the whole system ensure the problem will not be skipped and will be solved.

\section{Training System - HFDT}

Training of company staff is required in the WQMC system. TWM theory and ISO 3834 also require that business entities develop training activities for their personnel (SFSEN ISO 3834-2). In the WQMC system, the novelty is to build an up-to-date and localized welding personnel training strategy for China. In addition to its foundations on welding technology and production theory, this strategy employs the knowledge of psychology, pedagogy and behavioral science in order to establish training modules appropriate for contemporary circumstances in China, for welders as well as welding specialists, welding technicians, welding engineers, design engineers and welding inspectors. To some extent, managers and administrators in other roles are also considered for participation in the training in order to ensure that the same concept of welding and the WQMC system exists throughout the enterprise [12]. In this study, the training strategy is abbreviated to HFDT (human factor designed training system). 
Training content and lecture formats are discussed in this thesis. In the training method, the training modes are teaching and lectures, discussions, and audiovisual and case study methods. This study recommends adoption of 'small class' teaching methods in order to achieve better training quality. The small group size help to avoid distractions and improve focus. The passivity of large group lecture-based learning can induce fatigue and boredom in welding personnel. Furthermore, having a class with a large number of trainees means that it becomes difficult for the trainer to monitor and assist each trainee properly and respond to individual needs. Consequently, the objectives of the lectures are seldom totally met. Furthermore, small class teaching methods promote discussion and case study. Normally, the number of trainees in a small-group class ranges from 5 to 6 .

The content of the training builds and expands on welding theory; the following topics, among others, are addressed:

- Welding symbols and engineering drawing;

- Welding terms;

- Welding standards: ISO 3834 series, ISO 5817, ISO 9606, ISO 13920, ISO 15607, ISO 15609, ISO 15610ISO 15614, ISO 4136, ISO 5173, ISO 9015, ISO 9016, ISO 4063, ISO 6947, ISO 6520-1, GBT/324, GBT/3375, etc.;

- Welding defects and imperfections;

- Welding stress and deformations;

- Welding cracks and their causes;

- WPS concept and application;

- Welding inspections and experiments: destruction testing (DT) and non-destruction testing (NDT);

- Welding management strategies;

- Welding joints and welding structures production;

- Welding production knowledge for designers.

Table 1. The HFDT training lecture design content [13, 14, 15, 16, 17, 18, 19, 20, 21, 22, 23, 24, 25].

\begin{tabular}{|c|c|}
\hline Topics & Content \\
\hline Welding symbols and drawings & $\begin{array}{l}\text { Welding drawing and mechanical drawing reading; Welding symbols explanation; GB/T } 324 \text { and ISO 2553, welding } \\
\text { symbol representation on drawings; Link to drawings used in daily work to give further explanation. }\end{array}$ \\
\hline Welding technology terms & $\begin{array}{l}\text { Explanation of different terms used in daily work; Explanation of GB/T 3375, welding terms and Chinese national } \\
\text { standards; Explanation of ISO } 4063 \text { and ISO } 6947 .\end{array}$ \\
\hline $\begin{array}{l}\text { ISO } 3834 \text { and related } \\
\text { knowledge }\end{array}$ & $\begin{array}{l}\text { The main structure of ISO 3834; Welding quality management; Different parts of ISO } 3834 \text { (part2, part5 are the most } \\
\text { significant parts); The balance between cost and quality; implementation of ISO 3834; ISO } 3834 \text { and WQMC, the core } \\
\text { of WQMC system. }\end{array}$ \\
\hline ISO 9606 & $\begin{array}{l}\text { What is ISO } 9606 \text { and EN 287; The test selection principle and criteria; Test requirements and steps; Reading the } \\
\text { welder designation after the welder test. }\end{array}$ \\
\hline Welding deformation & $\begin{array}{l}\text { Reasons for welding deformation; Relationship between residual stress and welding deformation; Judging welding } \\
\text { deformation in current practices; Avoiding welding deformation during the processes. }\end{array}$ \\
\hline $\begin{array}{l}\text { Welding imperfections and } \\
\text { defects }\end{array}$ & $\begin{array}{l}\text { Concepts of welding imperfection and welding defects; The different kinds of welding defects; Explanation of each } \\
\text { welding defect: the reason and origin of the defect; How to avoid welding defect during the production steps; The } \\
\text { importance of ISO 5817; VT knowledge for welders and inspectors. }\end{array}$ \\
\hline $\begin{array}{l}\text { WPS knowledge and related } \\
\text { ISO standards }\end{array}$ & $\begin{array}{l}\text { The idea of WPS, WPQR, pWPS, and welding instructions; Explanation of ISO } 15607 \text { and ISO 15609; Explanation of } \\
\text { ISO } 15610 \text { to ISO 15613; Explanation of ISO } 15614 \text {. }\end{array}$ \\
\hline ISO 5817 & $\begin{array}{l}\text { The concept and explanation of ISO 5817; The concept of ISO } 6520-1 \text {; The different requirements for level B, C, and D } \\
\text { welding seams; Use ISO } 5817 \text { as the judgment document between welders and inspectors. }\end{array}$ \\
\hline Welding cracks and its origins & $\begin{array}{l}\text { The importance of avoiding welding cracks; The origins of cold cracking, hot cracking, reheat cracking, and lamellar } \\
\text { tearing; Methods to avoid different cracks; Importance of paying attention to the hydrogen and cleaning before } \\
\text { welding. }\end{array}$ \\
\hline $\begin{array}{l}\text { Welding seam DT and NDT to } \\
\text { inspectors }\end{array}$ & $\begin{array}{l}\text { Explanation of DT and NDT tests; Show the test specimen photos for DT tests; Short explanation of ISO } 4136 \text {, ISO } \\
5173 \text { ISO } 9015 \text { (part } 1 \text { and 2), and ISO 9016; Short explanation of PT, RT, UT, and MT. }\end{array}$ \\
\hline ISO 13920 & The requirement of welding seam tolerance in ISO 13920; The different welding seam tolerance levels in ISO 13920. \\
\hline $\begin{array}{l}\text { Welding strength knowledge for } \\
\text { designers }\end{array}$ & $\begin{array}{l}\text { Short explanation to the designers about welding seam mechanics; The strength of the welding joints; How to check the } \\
\text { welding handbook to ensure the strength. }\end{array}$ \\
\hline $\begin{array}{l}\text { Welding production knowledge } \\
\text { for designers }\end{array}$ & $\begin{array}{l}\text { The main steps of welding processes; Explanation of different welding processes (MIG, MAG, SAW, and TIG); } \\
\text { Importance of paying attention to the welding accessibility during the drawing design. }\end{array}$ \\
\hline Welding management strategy & $\begin{array}{l}\text { Layout of welding workshop; Welding environment issues; Total welding management concepts; LEAN theory; } \\
\text { WQMC system concepts; PDCA, 5S, 6sigma, and related concepts; Welding consumable and parent material storage. }\end{array}$ \\
\hline $\begin{array}{l}\text { New welding technologies and } \\
\text { new concepts introduction }\end{array}$ & $\begin{array}{l}\text { Laser welding and hybrid welding; Welding robots and semi-automatic welding processes; New technologies of } \\
\text { welding machines; Ergonomics during welding works; Advanced shielding gas information. }\end{array}$ \\
\hline
\end{tabular}

Clearly, the training content is not permanent and needs to change with developments in welding science and technology. The skills demanded of the trainer is an important research topic in this study. A knowledgeable, dutiful and well prepared trainer is required to ensure the success of the WQMC system and HFDT strategies. This research topic is expanded with reference to knowledge of training activities and training psychology.
The HFDT strategy is a tool which is built inside the WQMC system. Training, in this case, is defined as an implementation activity by the enterprise in order to promote the knowledge and working abilities of employees according to a well prepared, detailed plan [3]. The aim of the training is to update employees' knowledge, skills and activities as regards the topics emphasized in the training project, and encourage the application of this knowledge, skills and 
activities in their daily work. Furthermore, continuous learning requires that the employees understand the whole operation, and the steps and structures of the working system, which includes the connections between the different tasks, different departments, and even outsourced or subcontractor activities [4]. Welding training should follow the lead of modern manufacturing and incorporate information about modern innovations in both welding technology and training theory into courses at all levels [5]. The HFDT strategy exhibits the same characteristics as given in modern training theory. For example, in welding production, the HFDT strategy requires that the welders, designers, coordination team, managers, inspectors, and the welding upstream processes workers become familiar with each other and each other's work in order to fulfill the requirements of the continuous learning.

The welding knowledge training lectures are the most significant part in the HFDT strategy. In the case project, the training lectures are divided into 15 main topics. Table 1 lists the topics and key related content.

\section{Conclusion}

The complete implementation of the WQMC system includes several steps. Before the system implementation, the enterprise should make the decision to adopt the WQMC system, hold mobilization meetings for the employees, prepare the NEMS systems, and make a financial plan for the activities.

During the implementation steps of the WQMC system, the personnel structure analysis, the survey and interview work, the documentation work, the rectification of the manufacturing processes, the LCEPRS stage, the HFDT stage, the TWM and LEAN theory implementation, the modular design methodology implementation and the ISO 3834 requirements implementation should be all well planned and conducted.

After implementation of the WQMC system, the results discussion forums, the PDCA cycle and the future improvement plan should be established. Awareness among the personnel of the importance of welding quality and how welding quality is achieved is the most significant aim of the implementation of the WQMC system.

The flow chart below depicts the main steps in implementation of the WQMC system (Fig. 3): The WQMC system implemented in three different companies had positive results according to company statistics and feedback from welders, inspectors, and welding coordinators. The results indicate that the WQMC system is suitable for Chinese welding enterprises to utilize in their company management. The WQMC system will help Chinese welding enterprises to improve product quality and productivity, and decrease welding manufacturing cost.

The HFDT strategy helped the Chinese welding enterprises to improve the level of knowledge of their staff. Welding manufacturing and design personnel can get improved training from the implementation of this strategy.
The design of the training program, the qualifications of the trainer and the arrangement of the classroom were seen as effective drivers for the training developed in the three companies. Based on the results of this research, the HFDT strategy is suitable for use in Chinese welding enterprises.

The LCEPRS database is a concept that can help Chinese welding enterprises to improve their daily work not only from the production aspects, but also from the human factor, culture, and management aspects. The LCEPRS database can help Chinese welding enterprises to find and solve their inherent problems efficiently and easily based on the case project results and data collection.

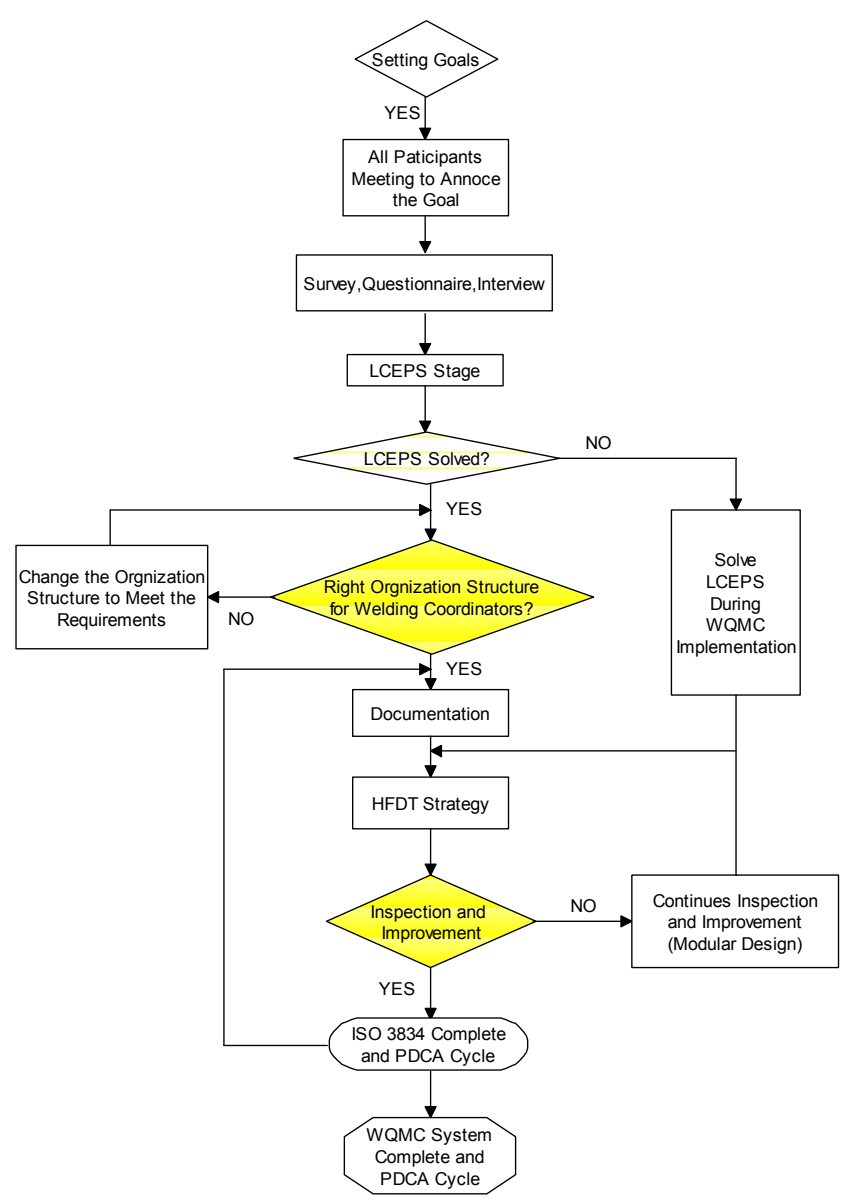

Fig. 3. Flow chart of WQMC system implementation.

In this research, only one company had launched the 'modular design' methodology. More examples of this approach in the future will help to verify the effects of the 'modular design' methodology.

Data collection and statistics is not very sufficient because some of the data is the confidential information in the company. More statistical data would definitely help to confirm the results of the WQMC system implementation. The data collected from company A and B is sufficient to illustrate the positive effect of the WQMC system.

Based on statistical data from the quality department in the enterprise, Figure $62(a, b)$ presents results of WQMC system implementation in Company B.

From the data of Figure 4, it can be seen that the total 
welding defect rate decreased from $9.3 \%$ to $5 \%$ during one year. And the wrong dimension, porosity, and other defects decreased from $5.4 \%$ to $3.1 \%, 2.8 \%$ to $1.4 \%$, and $1.1 \%$ to

\section{$0.5 \%$ respectively.}

Figure 5 presents the welding repair rate and the welding imperfection rate.

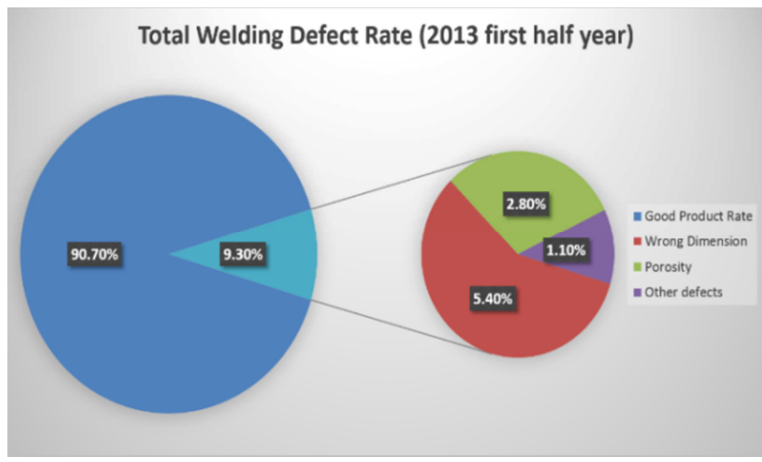

(a) Total welding defects before WQMC implementation.

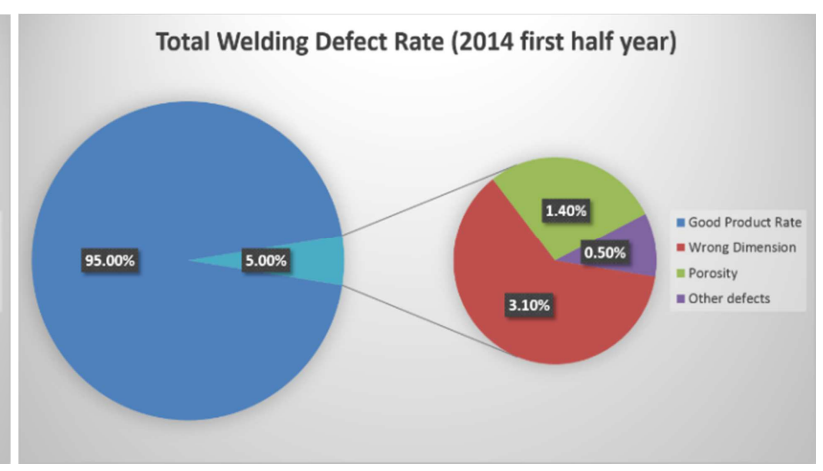

(b) Total welding defects after WQMC implementation.

Fig. 4. Total welding defect rate of Company $B$.

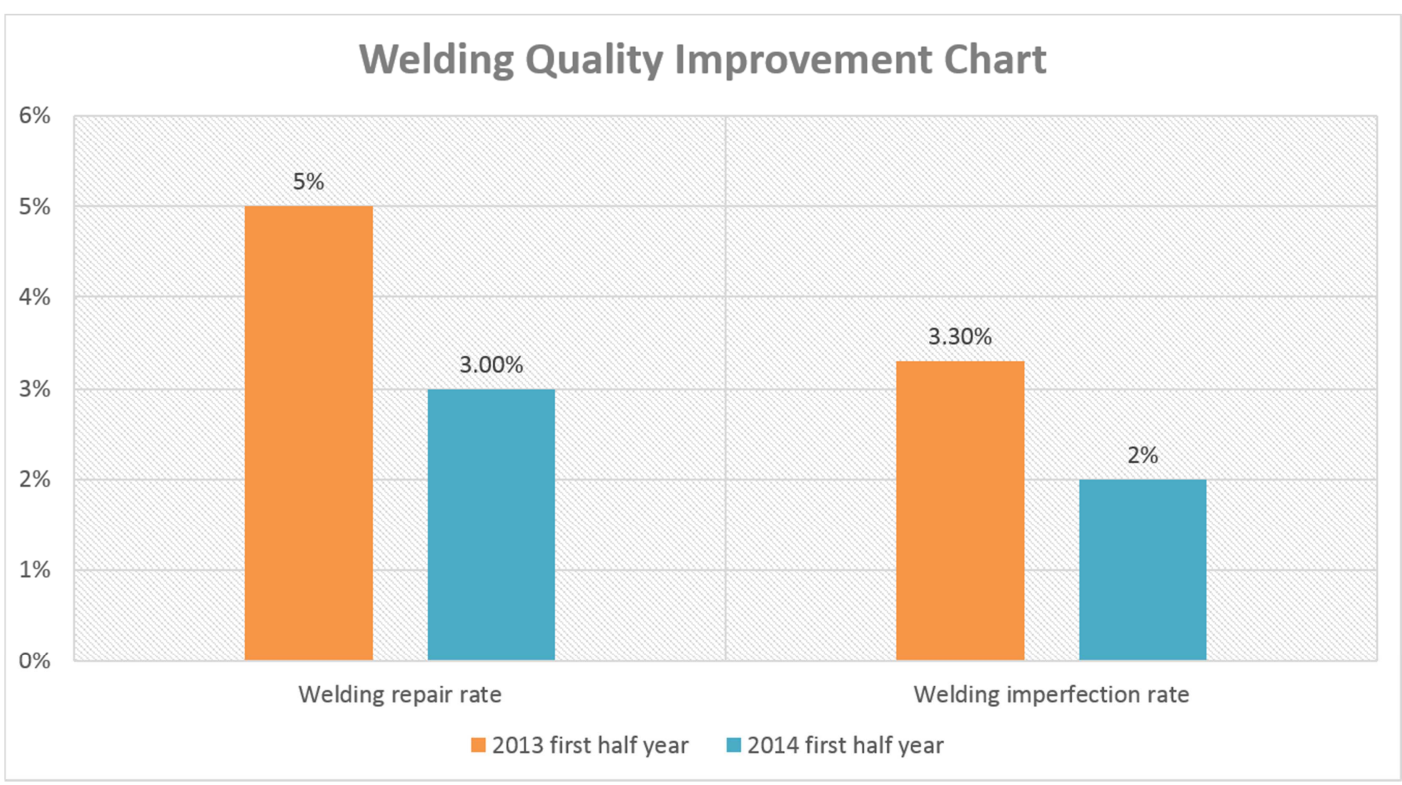

Fig. 5. Welding quality improvement of Company B.

From Figure 5, it can be seen that the welding repair rate decreased from $5 \%$ to $3 \%$, and the welding imperfection rate from $3.3 \%$ to $2 \%$ one year after implementation of the WQMC system.

According to the assessments, the basic research results are reached. The implementation of WQMC system gives the positive result for the companies in the case project.

The contribution of this paper is the finding, designing and building of the new welding manufacturing quality control management system implementing in China (name: welding production quality control management system in China: for short, WQMC system). This research is related to the management science, welding technology, and training technology and methodology. The new system will help the Chinese welding manufacturing enterprises (in different geographical areas, in different industrial areas, and in different company scales) to control their welding production quality in a certain high level, and management their welding manufacturing related personnel cooperate and work in an effective way by training. This research is important and have contribution because that the Chinese welding industry and foreign companies now all need the increasing quality and high productivity in the welding productions in China. Only when the Chinese welding factories have and implement a useful quality management control system now, that the two sides, China and foreign countries, can gain a win-win result in the welding production industries.

\section{References}

[1] Miao Chengdong, Yao Weimin, Zhang Jianzhong, The Theory of Modern Enterprise Management. - Peking University Press, ISBN 978-7-301-21032-1/F. 3269, 2012, 265 p.

[2] Chai Bangheng, ISO 9000 Quality Management System (Second Edition). - China Machine Press, ISBN 978-7-11131292-5, 2010, $401 \mathrm{p}$. 
[3] Noe A. Raymond, X. Fang, Employee Training and Development. - China Renmin University Press, ISBN 978-7300-08186-1, 2007, 428 p.

[4] Rosow J. M. and Zager R. Training the Competitiveness Edge. - San Francisco, Jossey-Bass, 1988 p.

[5] Polanin W. Richard The future of welding education. Welding journal, 2014, vol. 93, no. 4, p. 38-41.

[6] SFS-EN ISO 3834-6: en. 2007. Quality requirements for welding. Fusion welding for metallic materials. Part 6: implementation of ISO 3834-1 to - 5. Brussels: European Committee for Standardization (CEN). $21 \mathrm{p}$.

[7] SFS-EN ISO 3834-1: en. 2006. Quality requirements for fusion welding of metallic materials. Part 1: criteria for the selection of the appropriate level of quality requirements. Brussels: European Committee for Standardization (CEN). 7 p.

[8] SFS-EN ISO 3834-2: en. 2006. Quality requirements for fusion welding of metallic materials. Part 2: comprehensive quality requirements. Brussels: European Committee for Standardization (CEN). $10 \mathrm{p}$.

[9] SFS-EN ISO 3834-3: en. 2006. Quality requirements for fusion welding of metallic materials. Part 3: standard quality requirements. Brussels: European Committee for Standardization (CEN). 9 p.

[10] SFS-EN ISO 3834-4: en. 2006. Quality requirements for fusion welding of metallic materials. Part 4: elementary quality requirements. Brussels: European Committee for Standardization (CEN). 3 p.

[11] SFS-EN ISO 3834-5: en. 2006. Quality requirements for fusion welding of metallic materials. Part 5: documents with which it is necessary to conform to claim conformity to the quality requirements of ISO $3834-2$, ISO $3834-3$, or ISO 3834-4. Brussels: European Committee for Standardization (CEN). 19 p.

[12] Barckhoff R. J., 2007, Total Welding Management, China Machine Press, ISBN 978-7-111-20887-7, 167 p.

[13] Chen Qiang, 2007, Welding Manual volume 1 (Third Edition), China Machine Press, ISBN 978-7-111-22263-7, 1154 p.
[14] Lei Shiming, 2010, Welding Processes and Equipment, China Machine Press, ISBN 978-7-111-13617-0, 254 p.

[15] Liu Huijie, 2007, Welding Metallurgy and Weldability, China Machine Press, ISBN 978-7-111-20921-8, 246 p.

[16] Li Yajiang, 2005, Welding crystal structure performance and quality control, Chemical Industry Press, ISBN 7-5025-64683/TH.281, 356 p.

[17] Pan Jimin, 2010, Guidebook of Welder Operation Quality Assurance, ISBN 978-7-111-28350-8, 223 p.

[18] SFS-EN ISO 4063: en. 2010. Welding and allied processes. Nomenclature of processes and reference numbers (ISO 4063: 2009, corrected version 2010-03-01). Brussels: European Committee for Standardization (CEN). 21 p.

[19] SFS-EN ISO 5817: en. 2006. Welding. Fusion- welded joints in steel, nickel, titanium and their alloys (beam welding excluded). Quality levels for imperfection (ISO 5817: 2003, corrected version: 2005, including technical corrigendum 1: 2006). Brussels: European Committee for Standardization (CEN). 25 p.

[20] SFS-EN ISO 6520-1: en. 2008. Welding and allied processes. Classification of geometric imperfections in metallic materials. Part 1: fusion welding. Brussels: European Committee for Standardization (CEN). 49 p.

[21] SFS-EN ISO 6947: en. 2011. Welding and allied processes. Welding positions. (ISO 6947: 2001). Brussels: European Committee for Standardization (CEN). $17 \mathrm{p}$.

[22] SFS-EN ISO 9606-1: en. 2013. Qualification testing for welders. Fusion welding. Part 1: steels (ISO 9606-1: 2012 including COR 1: 2012). Brussels: European Committee for Standardization (CEN). 33 p.

[23] Wang Fengqing, 2009, The Development Research of the Internationalization of the Chinese Certification and Accreditation, China Standard Press, ISBN 978-7-5066-5545$3,115 \mathrm{p}$.

[24] Yin Shike, 2014, Welding Features and Welding Consumables for Low Carbon Steel, Chemical Industry Press, ISBN 978-7122-18703-1, $230 \mathrm{p}$.

[25] Zhao Xihua, 2009, Welding Inspection, China Machine Press, ISBN 978-7-111-03695-1, $201 \mathrm{p}$. 